\title{
Cultura no grupo de brinquedo
}

\author{
Ana Maria Almeida Carvalho \\ Universidade de São Paulo \\ Maria Isabel Pedrosa \\ Universidade Federal de Pernambuco
}

\begin{abstract}
Resumo
Discute-se o conceito de cultura em relação à microcultura do grupo de brinquedo. Concebe-se a criança como agente de criação e transmissão de cultura e o grupo de brinquedo como espaço de informação onde esses processos ocorrem. Essa concepção baseia-se no reconhecimento da espécie humana como biologicamente sócio-cultural e na pressuposição de adaptações precoces para essa especificidade. Episódios de atividade lúdica livre de crianças de 10 a 60 meses são analisados para detectar a ocorrência de criação, elaboração e transmissão de conteúdos culturais na interação criança-criança, ilustrando: (1) recuperação da cultura do ambiente social imediato e exploração de novas possibilidades de uso desses recursos; (2) criação de rituais lúdicos novos que podem tornar-se parte da microcultura do grupo; (3) aculturação, ou seja, assimilação de aspectos da microcultura do grupo. Os dados são interpretados como evidências da pré-adaptação humana para a vida sócio-cultural.
\end{abstract}

Palavras-chave: Interação social, Cultura da brincadeira, Ludicidade.

\begin{abstract}
Culture in the play group

This paper discusses the concept of culture in the context of playgroup microcultures. The child is viewed as an agent of culture creation and innovation, and the play group as a space of information where these processes occur. This view is based on the recognition of human species as biologically socio-cultural and on the assumption of precocious adaptations for this specificity. Episodes of free play activity among 10 to 60 month old children are analysed to detect the occurrence of creation, elaboration and transmission of cultural contents in child-child interactions, illustrating: (1) retrieval of the immediate social environment's culture and exploration of new possibilities of using these resources; (2) creation of new ludic rituals which can become part of the group's microculture; (3) aculturation, that is, assimilation of aspects of the group's microculture. Data are interpreted as evidences of the human pre-adaptation to a socio-cultural way of living.
\end{abstract}

Key words: Social interaction, Play culture, Playfulness.

$\mathrm{D}$ iscute-se neste trabalho o conceito de cultura em relação à microcultura do grupo de brinquedo, de um ponto de vista etológico e sócio-interacionista. Concebe-se a criança como agente de criação e transmissão de cultura, desde os primeiros anos, e o grupo de brinquedo como um dos espaços de informação em que esses processos ocorrem (Corsaro \& Molinari, 1990; Pedrosa, Carvalho \& Imperio-Hamburger, 1997; Pedrosa \& Eckerman, 2000; Pedrosa \& Santos, 2000). A partir de uma perspectiva etológica, essa concepção fundamenta-se no reconhecimento da espécie humana como biologicamente sociocultural e na pressuposição de adaptações próprias para essa especificidade que já se revelam na primeira infância. Em decorrência dessa perspectiva e dessa concepção, o ponto de vista sócio-interacionista de que a interação social é a matriz de construção do ser humano individual é incorporado como necessário para a compreensão dos processos de constituição simultânea do indivíduo e da cultura.

Cada um desses pressupostos requer alguma explicitação. A natureza biologicamente sociocultural do ser humano é uma concepção já antiga, embora ainda hoje sujeita a certa controvérsia quanto à compatilidade 
dos conceitos de biologia, sociedade e cultura. Já na década de 30 do último século, Wallon (1942/1979) explicita essa concepção exatamente com essas palavras, expressando uma visão integrada das ciências biológicas e humanas e uma perspectiva profundamente interacionista a respeito do desenvolvimento humano. Etólogos que dedicaram alguma reflexão e trabalho à espécie humana também reconhecem clara e explicitamente essa definição essencial do humano, intrínseca à noção etológica de fenômenos biopsicológicos como específicos da espécie e diretamente decorrente da observação do modo de vida humano através da história e das culturas - cf., por exemplo, Lorenz (1966), Eibl-Eibesfeldt (1989), Hinde (1974, 1987), Carvalho (1989a, 1998), Bussab e Ribeiro (1998), entre muitos outros. Morin (1979) critica enfaticamente as concepções que separam o homem em

(...) duas fatias sobrepostas, uma bionatural e outra psicossocial; é evidente que ele não é atravessado por qualquer muralha da China separando sua parte humana de sua parte animal". Propondo uma antropologia que recupere a unidade bio-psico-social do humano, esse autor complementa: "Como poderia o cérebro humano, que evidentemente só é funcional no seio de uma cultura, ter sido criado na 'natureza', se se concebe a natureza como oposta, independente ou anterior à cultura? (...) É perfeitamente evidente que o grande cérebro do sapiens só podia surgir, ser bem sucedido, triunfar, depois da formação de uma cultura já complexa, e é surpreendente que se tenha podido, durante tanto tempo, acreditar exatamente no contrário (p. 22).

Em termos evolutivos, a cultura é simultaneamente fruto e instrumento da seleção natural. Em termos ontogenéticos, o modo de vida sociocultural é o único modo de vida social que pode constituir um ser humano. Para esse modo de vida social a evolução criou adaptações específicas, que se manifestam desde o início da vida e que possibilitam que o desenvolvimento de um ser humano se dê, necessariamente, através da interação social em um ambiente sociocultural. (Bussab \& Ribeiro, 1998; Carvalho, 1989a, 1998; Rabinovich \& Carvalho, 2001).

A partir de pressupostos bem diversos, perspectivas culturalistas e sócio-históricas em Psicologia do Desenvolvimento também vieram a enfatizar o papel da interação social no desenvolvimento (Oliveira, 1995; Pino, 1993; Valsiner, 1991; Vygotsky, 1984). Uma convergência complementar entre perspectivas biológicas (ou psicoetológicas) e perspectivas sócio-históricas é a atenção ao papel ativo da criança na construção de sua história individual e, ainda, ao papel da interação criança-criança nesse processo desde os primeiros anos de vida. Desta forma, pode-se considerar praticamente consensuais na atual cultura da Psicologia do Desenvolvimento as noções a respeito da criança como agente ativo de seu desenvolvimento e do lugar da interação social e da interação criança-criança nesse processo (Camaioni, 1980; Carvalho, 1992; Pedrosa, 1989; Stambak \& Verba, 1986; Verba, 1994), ainda que nem sempre esses pressupostos conduzam às mesmas perguntas, níveis de análise e interpretações. Entre essas divergências, as que mais interessam ao presente trabalho se referem ao tratamento do conceito de cultura e às maneiras pelas quais a cultura constitui um contexto, espaço ou fator do desenvolvimento individual.

Corsaro (1985) usa o conceito de cultura (peer culture) para se referir ao conjunto de atividades e rotinas, artefatos, valores e interesses compartilhados pelo grupo de pares de idade, sejam originados do mundo adulto ou criados e transformados no próprio grupo. Nesse mesmo sentido, temos investigado, em nosso trabalho, as formas de criação e de transformação de normas, maneiras de brincar, etc., no grupo social composto por crianças de mesma idade ou de idade próxima, em um contexto de interação livre (Carvalho, 1989b; Pedrosa \& Santos, 2000; Pedrosa \& Eckerman, 2000). Esse uso, já relativamente consagrado na literatura sobre interação criança-criança, não nos exime, no entanto, de uma reflexão sobre os sentidos de cultura e sobre as relações entre a microcultura do grupo de brinquedo e a estrutura sociocultural da sociedade mais ampla onde ele está inserido (Hinde, 1987). Terá a peer culture as mesmas propriedades emergentes e supra-individuais que caracterizam a estrutura sociocultural mais ampla? Como, concretamente, se dá a inserção da criança nesse mundo sociocultural e qual o papel da interação interpessoal nessa inserção? De que formas se assemelham ou se diferenciam os processos culturais humanos - seja em nível micro ou macro - e os processos, às vezes chamados protoculturais, que vêm sendo cada vez mais evidenciados em outras espécies, especialmente em primatas? É na direção dessas reflexões que este trabalho se encaminha, através da análise de episódios de interação de crianças pequenas em situações de atividade livre com pouca interferência de parceiros culturalmente mais experientes.

\section{Alguma coisa sobre método}

Os episódios a serem analisados aqui foram obtidos através de vídeo-gravações em diversas instituições de atendimento à criança pré-escolar ao longo de vários anos. As instituições variam em termos de nível sócio-econômico da população atendida, localidade (São Paulo, Carapicuiba e Recife), ambiente físico (berçário, sala de recreação, pátio), idade das crianças focalizadas (10-18 meses, 12-24 meses, 24-60 meses), composição dos grupos de brinquedo (faixa etária homogênea ou heterogênea, número de crianças por grupo, razão adulto-criança) e duração do período de acompanhamento do grupo (de seis meses a dois anos). Em todos os casos, os registros 
foram feitos em situações de atividade livre, sem interferência de adultos na orientação ou proposição de brincadeiras, em sessões semanais ou quase semanais de duração variável (20 a 60 minutos). O critério de filmagem adlib privilegiou a apreensão de seqüências de atividades conjuntas de pelo menos duas crianças, sem recortes temporais rígidos, de forma a maximizar a captação de processos de regulação mútua e de co-construção de atividades. O conjunto desses registros compõe o banco de dados a partir do qual os episódios são selecionados para análise de questões específicas. Um episódio é definido quando se apreende uma seqüência interativa conspícua ou um trecho do registro em que se pode circunscrever um grupo de crianças a partir do arranjo espacial que formam e/ou da atividade que realizam. $\mathrm{O}$ término de um episódio pode ser definido com base em uma mudança de tema da brincadeira, em sua interrupção por um agente externo (por exemplo, o adulto), por uma mudança na composição do grupo. A delimitação de um episódio, tanto em termos de início como de término, envolve portanto um grau de arbitrariedade que reflete a participação do pesquisador na construção do dado: é o observador, com suas hipóteses e sua interação com os fatos observados, quem determina essa delimitação (Carvalho et al., 1996; Carvalho, Império-Hamburger \& Pedrosa, 1999; Pedrosa, 1989).

\section{Trazendo a "macrocultura" para o grupo de brinquedo}

Relato 1: Ricardo (4 anos) trouxe para a escolinha um cavalo de pau e um chapéu de vaqueiro. Edu (4a) toma emprestado o chapéu. Encontra-se no gramado com Gabriel, Roni e Pedro (5a). Edu grita: "Eu sou Sinhozinho Malta!". Os outros respondem: "Oi, Sinhozinho Malta! Ele não é sinhozinho Malta, é a Viúva Porcina! Sinhozinho Malta, por favor não me mate!'. Estabelece-se imediatamente uma brincadeira de pega-pega (perseguição ou 'playchasing'), em que Edu é Sinhozinho Malta e os demais são seus perseguidores, perseguidos ou capangas, entre gritos de estímulo, propostas e invocações: "Sinhozinho Malta, você não me pega! Você é o capanga de Sinhozinho Malta! Sinhozinho Malta vem vindo, hein? Cadê minha espingarda?". Um pedaço de pau torna-se uma espingarda nas mãos de Gabriel, Roni se torna um boi, que é laçado por Pedro. As crianças correm e se perseguem, entre gritos, risos e outras verbalizações, pelos vários espaços externos disponíveis. Embora Ricardo tenha pedido e recebido de volta seu chapéu cerca de um minuto e meio depois do início da brincadeira, esta continua por pelo menos mais 30 minutos, até o final da sessão de observação.

$\mathrm{O}$ rápido desencadeamento dessa brincadeira, seu enriquecimento e sua duração podem ser entendidos diante da evidência de um conhecimento já previamente compartilhado pelos parceiros, que não é, neste caso, o conhecimento de uma brincadeira tradicional, previamente ensinada, mas o de significados construídos em outro contexto. A novela Roque Santeiro, sucesso de audiência na época (1985/6), e assistida provavelmente com regularidade por estas crianças, ofereceu os elementos para a criação coletiva de um enredo de brincadeira que, sem reproduzir o enredo da novela, fluiu sem dificuldades graças ao conhecimento comum que as crianças possuíam sobre os personagens, seu comportamento, seus possíveis papéis: por exemplo, o chapéu usado por Edu lhe acarreta o papel de Sinhozinho Malta e o torna alvo da animosidade de outros personagens, perseguidor desses inimigos ou chefe de capangas. Até o boi - que na novela é um personagem secundário, presente pelo fato de Chico Malta ser um fazendeiro de gado - é aproveitado para criar uma seqüência de corrida, perseguição e captura. Uma vez desencadeado o enredo, a retirada de seus suportes materiais (o chapéu e o cavalo de Roberto) não impede sua seqüência: outros objetos são introduzidos (corda, espingarda) e/ou o enredo se liberta de suportes materiais e se apóia nas trocas verbais e gestuais.

A fluência e a duração de brincadeiras de perseguição com elementos de fantasia, muito comuns nessa faixa etária, especialmente entre meninos (Moraes \& Carvalho, 1994), parecem ser função (entre outros fatores) da possibilidade de propostas e atribuições de papéis que alcancem certo consenso entre os participantes, ou seja, cujo significado possa ser compartilhado e avaliado como pertinente. Trazer para a brincadeira elementos da macrocultura compartilhada é uma estratégia comum e em geral bem sucedida nesse sentido. Esta estratégia também permeia a proposição e aceitação de regras que coordenam a brincadeira: na classificação de Moraes e Carvalho (1994), regras derivadas do conhecimento da natureza ("leão não fala", "vulcão não tem porta"), de usos e costumes sociais (mãe abraça; pai sai para trabalhar), de histórias consagradas (contos de fadas ou, mais comumente em nossa cultura, heróis e personagens de TV, como no exemplo acima).

Ao trazerem elementos da macrocultura para a situação de brincadeira, as crianças assumem também um papel ativo em sua transmissão para os parceiros. Isso é particularmente claro em relação a brincadeiras tradicionais, cuja dinâmica e regras são transmitidas pelas crianças mais velhas e mais experientes para os parceiros mais jovens nos grupos multi-etários ainda comuns em cidades pequenas e em periferias de grandes centros urbanos (Pontes \& Magalhães, no prelo).

Em certos casos, é possível observar uma transmissão mais direta, quase que um ensinamento, como no episódio resumido a seguir. 
Relato 2: Julia ( $2 \mathrm{a} 8 \mathrm{~m}$ ) está brincando com peças de madeira. Nina (2a11m) se aproxima e diz: "Posso brincar com você?", senta-se e passa a manipular as peças, empilhando-as e encaixando-as. Julia observa e imita. Nina começa a bater palmas e cantarolar "Parabéns". Julia imita as palmas sorrindo, sem cantar. Nina pára de cantar, volta a manipular as peças e reinicia a seqüência, cantando "Parabéns". Olha para Julia, que está em pé, de costas para ela, levanta-se, aproxima-se e puxa Julia pelo braço: "Vamos cantar parabéns, Julia?". Agacham-se ambas diante das peças. Nina: "Vamos começar, primeiro aqui... péra aí, Julia...". Julia começa a bater palmas, Nina interrompe: "Péra aí, Julia, você fica aqui, eu fico aqui ...". Começa a bater palmas e cantar, Julia acompanha as palmas. Nina canta "Parabéns" até o final e grita "Viva! É pique, é pique... é hora, é hora, é hora", sempre batendo palmas acompanhada por Julia. Nina desmancha o "bolo" e recomeça a manipulação das peças. Há uma interrupção enquanto Julia sai para ir ao banheiro. Nina volta a manipular as peças, levanta e diz: "Vou lá com a Julia". Chama alto: “Julia, Júlia... vamos cantar parabéns!". Julia se aproxima, começa a entoar o "Parabéns". Nina interrompe: "Não, péra aí... vem cá...”. Julia senta-se diante de Nina e começa: "Parabe...". Nina: "Não, péra aí, Julia... agora!" e começa a cantar batendo palmas. Julia canta, sem bater palmas, Nina interrompe novamente: "Não, faz assim" e bate palmas. As duas cantam juntas e batem palmas, olhando-se e sorrindo. Nina canta sozinha um segundo verso, enquanto Julia bate palmas. Quando Nina termina, Julia canta: "É pique, é pique...". Nina acompanha e finaliza: "Viva Julia!". A brincadeira é repetida mais duas vezes, desmontando e montando as peças, e cantando "Parabéns" acompanhado de palmas e de "é pique", sempre com Nina dando o ritmo de andamento.

Observa-se aqui como a atividade e o conhecimento partilhados vão sendo construídos no decorrer do episódio. O rito do "Parabéns" parece, no início, já ser conhecido de Julia, que o aceita com facilidade e prazer. No entanto, Julia não domina o rito na mesma extensão que Nina: não parece capaz de cantar independentemente a letra nas primeiras ocasiões em que Nina faz essa proposta, nem de coordenar o canto com outras ações. Na segunda parte do episódio, Julia acompanha mais ou menos precariamente as palavras do primeiro verso (cantando atrás de Nina) e se cala quando Nina canta o segundo; mas, assim que Nina pára, é Julia quem introduz o "É pique!”, que Nina acompanha prontamente. Nas últimas duas seqüências, as ações das duas crianças mostram-se progressivamente mais coordenadas.

A presença da macrocultura no grupo de brinquedo revela-se também através de papéis e valores - por exemplo, na estereotipia de gênero em relação a brincadeiras (Carva- lho, Beraldo, Santos \& Ortega, 1993; Carvalho, Smith, Hunter \& Costabile, 1990), na formulação de regras baseadas em conhecimento social ou na recusa de papéis menos valorizados socialmente pelas crianças que lideram uma brincadeira (Moraes \& Carvalho, 1994).

Trazer valores e conceitos da macrocultura para a brincadeira é uma oportunidade de questioná-los, de reconstruílos ou de fortalecê-los, dependendo da interação com conceitos e valores dos parceiros. Harris (1995) sugere que o grupo de pares é o principal responsável pelo desenvolvimento de atitudes e valores desde a infância, possivelmente superando o papel dos adultos nesse processo.

\section{Construindo cultura no grupo de brinquedo}

Regras organizadoras da brincadeira também podem ser construídas arbitrariamente pelas crianças no grupo de brinquedo. Moraes e Carvalho (1994) exemplificam regras arbitrárias (e muitas vezes bastante oportunistas!) tais como "Só o meu revólver é que mata de verdade", criadas pelo líder (em geral o proponente) da brincadeira e acatadas, ou não, pelos demais participantes. Evidenciam também o papel da regra na estruturação dos papéis e na coordenação do comportamento dos participantes da brincadeira, cuja continuidade e fluência dependem da compreensão e aceitação compartilhadas das regras.

Um outro exemplo, curioso por se tratar de proposição de uma regra "moral", no sentido de reguladora de condutas sociais, é oferecido pelo episódio seguinte (Carvalho, 1989b, p. 209):

Relato 3: Susana (3a), Lia (3a), André (3a 6m) e Rafael ( 3 a $6 \mathrm{~m}$ ) brincam próximos no tanque de areia. Ao se movimentar, Rafael espirra areia em Lia, que se volta para ele e fala, em tom forte: 'Bobo!'. André intervém: 'Ele não é bobo não!'. Lia se afasta. Susana, que observa o episódio, sentase ao lado de André e diz, em tom bem explicado e pausado: 'André, se a pessoa não joga areia na gente, não pode falar 'Bobo'. Se a pessoa joga areia na gente, pode falar 'Bobo'!".

Mesmo em crianças bem pequenas pode-se observar a construção coletiva de conteúdos culturais tais como enredos de brincadeiras, com potencial de persistência no grupo. Pedrosa e Carvalho (1995) descrevem um episódio no qual duas crianças constroem uma brincadeira de deitar/ sentar em turnos. Em um dos primeiros turnos, uma delas diz:"Dêta!" imediatamente após a outra ter se deitado. Ao longo do episódio, a palavra é usada várias vezes pela mesma criança que a introduziu, sinalizando inicialmente o turno, depois um convite à brincadeira, que acaba incorporando outras crianças. A palavra "Dêta" tem seu significado reconstruído nesse contexto interacional e nesse grupo de parceiros, passando a sinalizar uma determinada forma de brincar. 
Um outro exemplo ilustrativo encontra-se em Pedrosa e Eckerman (2000): duas crianças (Jef, 17 meses, e Lala, 10 meses) são os principais protagonistas de um episódio de ação coordenada, em que várias crianças arrastam uma mesinha de um lado para outro da sala da creche. Três semanas depois, esses mesmos parceiros restauram um episódio de empurrar / puxar objeto grande, no caso uma cadeira. A brincadeira se organiza rapidamente, persiste e outros parceiros são preteridos, o que indica que esses parceiros compartilham significados construídos anteriormente; em outras palavras, partilham a microcultura do grupo de brinquedo.

Løkken (2001) descreve rituais de saudação criados por crianças de cerca de dois anos e utilizados para receber um amiguinho que chega à creche: por exemplo, em um deles, as crianças surpreendem a recém-chegada surgindo de detrás de uma estante, pulando diante dela em turnos e gritando "Waah!", iniciando um jogo de gestos e vocalizações ritualizadas; a criança recém-chegada ri e vocaliza em resposta e todos seguem do corredor de entrada para a sala de jogos, correndo e gritando "Waah". A criação de formas idiossincráticas de saudação é um fenômeno facilmente observável em vários tipos de subgrupos humanos: parceiros de um time esportivo, companheiros de acampamento ou de viagem, as várias "tribos" que caracterizam os grupos de pares na adolescência. Essas formas de saudação (bem como uma série de outros rituais e práticas) identificam o pertencimento ao grupo e fazem parte de sua identidade. As observações de Løkken demonstram a precocidade com que seres humanos se engajam no processo de identificação cultural e de transformação da cultura de seu ambiente social imediato.

\section{Assimilando a cultura do grupo de brinquedo}

Ao longo da vida, qualquer ser humano - criança, adolescente, adulto - tipicamente passa por diversas experiências de contato com novos grupos sociais: no ingresso à escola, à universidade, ao trabalho, a ambientes sociais novos, a uma nova família extensa em decorrência do casamento, a populações culturalmente bem distintas no caso de viagens mais longas. $\mathrm{O}$ grau de diversidade dessas experiências evidentemente varia ao longo da história e dos modos de vida de diferentes populações: ainda hoje, há pessoas que jamais saíram ou sairão da pequena vila onde nasceram; mesmo estas, no entanto, não estão necessariamente imunes ao contato com microculturas diferentes ou com faces diferentes de sua própria cultura. Quando esses contatos envolvem transições mais bruscas ou dramáticas, é comum até mesmo a ocorrência de ritos de passagem, que recortam e dão significado à situação de transição para os indivíduos envolvidos.
De certa forma, a adaptação da criança pequena a um ambiente de cuidado coletivo tem essa característica de transição cultural. Essa transição é especialmente marcante em nossa sociedade urbana atual, onde a criança é deslocada de seu ambiente familiar para um ambiente físico e social bem diferenciado daquele; em sociedades mais tradicionais, ela ocorre de forma mais gradual, à medida que a criança passa a brincar com irmãos ou vizinhos, geralmente sob a supervisão de adultos com quem já está familiarizada. Em qualquer desses casos, existe a exposição a diferenças microculturais.

Ao lado das dimensões afetivas dessa transição que já têm sido focalizadas na literatura (cf., por exemplo, RossettiFerreira, Amorim \& Vitória, 1996; 1997; Vitória \& RossettiFerreira, 1993), a observação de crianças pequenas nesse processo ilumina a ocorrência de um processo ativo de assimilação cognitiva das características culturais do novo ambiente, que vai permitir que a criança organize suas condutas e intervenções nesse ambiente. Essas características culturais abrangem tanto a organização física quanto social do ambiente: Quais espaços existem? Quais podem ser utilizados, e para quê? Onde ficam os vários tipos de brinquedos? Quem costuma brincar onde? Com quem? De quê? Como brincam? Para que são usados os vários tipos de objetos disponíveis? e assim por diante. Crianças novatas que chegam a um grupo de brinquedo podem gastar um tempo significativo observando outras crianças e suas atividades, antes de se engajarem elas próprias em atividades solitárias ou conjuntas; também é freqüente que a criança novata passe boa parte do tempo próxima do adulto, que possivelmente constitui para ela a referência mais familiar. Inúmeras observações indicam, no entanto, que a outra criança, sua atividade e suas interações com parceiros são alvos privilegiados de atenção nessa situação (Branco, Carvalho, Gil \& Pedrosa, 1989; Carvalho, 1989b).

O processo de assimilação da microcultura do grupo de brinquedo torna-se especialmente claro quando se trata de uma criança que, por alguma circunstância, provem de uma microcultura diferenciada. É o caso de Jonas, que ingressou no grupo de brinquedo aos três anos, e foi acompanhado nas observações ao longo de um ano e meio. Segundo as informações das educadoras, Jonas era filho único de uma família bastante formal e exigente quanto à sua aparência e maneiras; além disso, ficou evidente desde as primeiras observações que Jonas era dotado de uma capacidade verbal excepcional para sua idade.

$\mathrm{Na}$ ocasião de seu ingresso, Jonas encontrou um grupo composto por quatro meninos mais velhos, quatro meninos de sua idade (entre os quais, dois novatos como ele). Dois meninos de sua idade atraíram mais sua atenção: Fernando, veterano, e Nicolau, também novato. 
Ambos eram muito ativos fisicamente e apresentavam uma verbalização tipicamente infantil em termos de entonação (com muitas inflexões e tons de interrogação: "néeee"?) e de pronúncia (por exemplo, substituindo os sons de "ce" por "xe" - "voxê" por "você"; "r" por "l" "quelo" por "quero"; omitindo " $\mathrm{r}$ " em sílabas complexas - "bincá" por "brincar", "quebá" por "quebrar", e utilizando muitas interjeições e gesticulação). Em contraste, Jonas movimentava-se comedidamente; suas poucas verbalizações ao longo das quatro primeiras semanas foram dirigidas ao adulto para pedir ajuda: "eu quero brincar com aquele carrinho", apontando o caminhão com que outro menino brincava; ou "conserta pra mim?", mostrando um brinquedo que trazia na mão. O comportamento típico de Jonas nesse primeiro período era ficar em pé próximo a um grupo de crianças brincando e observálas atentamente. Nunca foi visto tomando um objeto de outra criança. Na segunda semana, foi visto abaixandose momentaneamente no tanque de areia e erguendo-se em seguida, batendo as mãos para limpá-las da areia.

Ao longo do primeiro semestre, em observações semanais, observam-se modificações graduais no comportamento de Jonas. Depois de algumas semanas ele senta na areia e brinca sozinho com objetos disponíveis. Tem interações verbais isoladas com algumas crianças, em geral de conteúdo formal: "um dia eu vou na sua casa"; pede licença ao parceiro para pegar ou manipular objetos (por exemplo, a Fernando: “pode pegar esse?"). Em alguns momentos, dá a impressão de não entender a verbalização da outra criança (por exemplo, pergunta repetidamente "o quê?" quando Nicolau the diz algo). Continua a observar atentamente as atividades e interações de outras crianças e, eventualmente, começa a imitar suas verbalizações. Sua imitação é muito perceptível, apesar da má qualidade da gravação de áudio, pela enorme diferença de pronúncia entre ele e os parceiros. Por exemplo, brincando com Fernando e Nicolau dentro de uma cabaninha, Fernando diz: "Aqui é a caja de nóis"; Jonas repete: "aqui é a casa de nós". Fernando grita: “Tchau kianxada! Xai da noxa caja!"; Jonas repete, também gritando: "Sai da nossa casa!". Em uma sessão no início do quarto mês, Jonas mantém um diálogo longo com Nicolau sobre a brincadeira com caminhões em que estão envolvidos. Jonas diz: "Meu caminhão é de fogo...". Nicolau: "é bombeiro, néee?". Jonas, em tom de confirmação: "É, é bombeiro". Os dois meninos arrastam os caminhões produzindo sons de motor "brrrr".

Depois de quatro meses de convivência, encontramos Jonas já engajado em uma relação estável com Nicolau. Pode-se dizer que está irreconhecível: ao chegar à creche, livra-se rapidamente de seu casaco e sapatos, dirige-se para o tanque de areia onde em geral seus par- ceiros estão brincando com areia, água e caminhões, senta-se junto deles e inicia uma atividade imitativa ou complementar, emitindo verbalizações lúdicas e risos. Pela primeira vez nas sessões de observação, observa-se uma pronúncia infantil de Jonas, respondendo a Nicolau que perguntou: "Vamo tabaiá?" - "Vamo tabalhá...", seguida de risos de ambos. Em outros momentos, Jonas ainda se dirige a Nicolau em entonação afirmativa, como um adulto falando com uma criança pequena: Nicolau se queixa "Bati na minha mão!" e Jonas responde: "Já passou... Vem, Nicolau... Vai buscar o caminhão, vai...”.

Após mais alguns meses, é difícil distinguir a verbalização de Jonas e a de Nicolau. Ao se dirigir aos parceiros, Jonas agora apresenta mais expressões corporais, interjeições, risos, gritos e outros ruídos do que verbalizações formais; usa entonações infantis, frases simplificadas e até pronúncia infantil. Também apresenta mais movimentação corporal e usa o espaço de forma mais ampla.

É como se Jonas tivesse aprendido uma nova língua e novos modos de se comunicar: aqueles que eram compartilhados por seus pares, e com base nos quais ele poderia partilhar e co-construir a cultura do grupo. Um aspecto especialmente interessante deste caso é que a "aquisição" de Jonas parece representar, em termos estritamente de desenvolvimento, uma regressão: ele aprende formas de comportamento e de linguagem mais imaturas do que as que apresentava ao ingressar no grupo. Do ponto de vista do processo sociocultural, no entanto, trata-se de uma aculturação, processada ativamente por Jonas através de observação e imitação.

\section{Cultura e protocultura}

Pode-se designar como cultura esses fenômenos interacionais observados no grupo de brinquedo? Tomasello, Kruger e Ratner (1993) sustentam que os fenômenos culturais humanos, inclusive os observados na primeira infância, são qualitativamente diversos dos que se observam em outros primatas por se basearem em mecanismos de aprendizagem específicos da espécie, ou seja, adaptações próprias para a vida cultural. Segundo sua proposta, a aprendizagem cultural seria possibilitada por três processos que se diferenciam ao longo da ontogênese. A aprendizagem por imitação, que apareceria tipicamente a partir dos nove meses, sob a forma de imitação "verdadeira", envolveria a internalização de estratégias comportamentais utilizadas pelo agente imitado (diferindo, portanto, da imitação que envolve apenas a consecução de objetivos através de métodos próprios, não imitados, e que seria típica de outros primatas); a aprendizagem por instrução (que ocorreria a partir dos quatro anos), típica da relação adultocriança e destacada na teorização de Vygotsky como internalização, pelo aprendiz, das instruções do instrutor 
e uso posterior dessas instruções para auto-regular suas funções cognitivas; e a aprendizagem colaborativa, que surgiria a partir da idade escolar, em que pares constroem em conjunto um conhecimento que nenhum deles possuía anteriormente. Essas etapas envolveriam qualidades crescentes de intersubjetividade, desde atenção conjunta e referenciamento social, que possibilitariam adotar a perspectiva do outro e seriam o fundamento da imitação verdadeira, até a chamada intersubjetividade reflexiva, em que os parceiros se atribuem mutuamente intenções e estados mentais ("Ele pensa que eu penso que...”).

Tanto essas etapas ontogenéticas quanto a diferenciação qualitativa proposta pelos autores entre seres humanos e outros primatas em relação a essas formas de aprendizagem têm sido objeto de controvérsia. Assim, por exemplo, em seu comentário ao trabalho de Tomasello et al. (1993), Braten (1993) argumenta que crianças pré-escolares já apresentam aprendizagem colaborativa: ao criarem uma brincadeira de faz-de-conta, estão constituindo simetricamente uma díade co-criativa, cujas ações não são apenas imitações diferidas ou frutos de instrução anterior, mesmo que ainda não exista um conceito de "outra pessoa" no sentido de intersubjetividade reflexiva: "Even if learning is not mediated by a reflective agency concept of 'person', something new in a cultural sense is co-created in such symmetric peer interaction..." (p. 515). Braten atribui essa possibilidade de aquisição cultural à capacidade precoce da criança para envolver-se com sentimentos do outro, o que se manifesta já nos contatos entre bebês de três meses através de olhares recíprocos, sorrisos, vocalizações e tentativas de toque (Field, 1990, citado por Braten 1993). Várias de nossas observações endossam essa interpretação.

Sob outro ângulo, Bruner (1993) critica o uso que os autores fazem dos conceitos de aquisição e de aprendizagem, sugerindo que são resquícios de teorias de aprendizagem já superadas e da noção profundamente enraizada de que é o indivíduo que aprende (ou adquire) o social.

Só em um sentido muito banal 'adquire-se' cultura: 'entrase' na cultura, se é 'capacitado' por ela, ou, para emprestar um termo de Geertz (1973), se é ‘constituído’ por ela. A cultura não é um conjunto de respostas a serem aprendidas, é uma forma de conhecimento, de conceber o mundo e os outros (p. 516).

Byrne (1993) coloca em discussão o argumento de Tomasello et al. (1993) de que nenhum animal em situação natural apresentaria qualquer dos três processos de aprendizagem propostos como requisitos para a vida cultural. As evidências a respeito de imitação "verdadeira" e de aprendizagem por instrução em primatas mereceriam uma consideração mais cuidadosa e tornariam prematuro esse tipo de afirmação.

Essas controvérsias, entre outras, sinalizam a efervescência atual do tema "cultura" na Psicologia do
Desenvolvimento e na Psicologia Comparativa. Quer se considere que o modo de vida sociocultural é uma emergência devida a adaptações específicas da espécie, ou a uma combinação peculiar de mecanismos presentes de forma isolada em outras espécies - que se revelam, por exemplo, em manifestações protoculturais de outros primatas, é consensual que o ser humano é a única espécie cuja sobrevivência e evolução estão intrinsecamente ligadas a um modo de vida cultural. Recorrendo novamente a Morin (1979, p. 62),

... O grande cérebro teria sido uma desvantagem para um ser que não dispusesse dessa complexidade (sócio-cultural)... Privado de cultura, o sapiens seria um débil mental, incapaz de sobreviver a não ser como um primata do mais baixo nível; nem mesmo poderia reconstruir uma sociedade de complexidade igual à dos babuínos e dos chimpanzés.

Nesse sentido, poderia ser justificada a distinção entre manifestações culturais e protoculturais, estas últimas referindo-se aos casos em que fenômenos culturais ocorrem de forma isolada, não constituindo parte da adaptação básica de uma espécie.

Pelo mesmo argumento justifica-se também, a nosso ver, o uso do conceito de cultura para nos referirmos aos processos interacionais entre crianças pequenas. Mais do que isso, a investigação detalhada desses processos a partir do ângulo da cultura como constituinte e constituída pelos indivíduos em interação em seus grupos sociais imediatos, desde a primeira infância, pode contribuir para a compreensão dos mecanismos criados por nossa história evolutiva que subjazem à especificidade humana.

\section{Referências}

Branco, A. U. A., Carvalho, A. M. A., Gil, M. S. A., \& Pedrosa, M. I. (1989). Fluxo de interações entre crianças numa situação de brinquedo em grupo. Psicologia, 15, 13-27.

Braten, S. (1993). Social-emotional and auto-operational roots of cultural (peer) learning. Behavioral and Brain Sciences, 16, 515.

Bruner, J. (1993). Do we "acquire" culture or vice versa? Behavioral and Brain Sciences, 16, 515-516.

Bussab, V. S. R., \& Ribeiro, F. L. (1998). Biologicamente cultural. In L. Souza, M. F. Q. Silva \& M. M. P. Rodrigues (Orgs.), Psicologia - Reflexões (im)pertinentes (pp. 175-194). São Paulo: Casa do Psicólogo.

Byrne, R. W. (1993). Hierarchical levels of imitation. Behavioral and Brain Sciences, 16, 516-517.

Camaioni, L. (1980). L'interazione tra bambini. Roma: Armando Armando.

Carvalho, A. M. A. (1989a). O lugar do biológico na Psicologia: O ponto de vista da Etologia. Biotemas, 2, 81-92.

Carvalho, A. M. A. (1989b). Brincar juntos: natureza e função da interação entre crianças. In C. Ades (Org.), Etologia: de animais e de homens (pp.199-210). São Paulo: Edicon/ Edusp.

Carvalho, A.M.A.(1992). Seletividade e vínculo na interação entre crianças. Tese de livre-docência não-publicada, Universidade de São Paulo, São Paulo.

Carvalho, A. M. A. (1998). Etologia e comportamento social. Em L. Souza, M. F. Q. Silva \& M. M. P. Rodrigues (Orgs.), Psicologia - Reflexões (im)pertinentes (pp. 195-224). São Paulo: Casa do Psicólogo. 
Carvalho, A. M. A., Beraldo, K. E. A., Santos, M. F., \& Ortega, R. (1993). Brincadeiras de menino, brincadeiras de menina. Psicologia, Ciência e Profissão, 13, 30-33.

Carvalho, A. M. A., Bergamasco, N. H. P., Lyra, M. C. D. P., Pedrosa, M. I., Rubiano, M. R. B., Rossetti-Ferreira, M. C. T., Oliveira, Z. M. R., \& Vasconcellos, V. M. R. (1996). Registro em vídeo na pesquisa em Psicologia: reflexões a partir de relatos de experiência. Psicologia: Teoria e Pesquisa, 12, 261-267.

Carvalho, A. M. A., Império-Hamburger, A., \& Pedrosa, M. I. (1999). Dados e tirados: teoria e experiência na pesquisa em Psicologia. Temas em Psicologia, 7, 205-212.

Carvalho, A. M. A., Smith, P. K., Hunter, T., \& Costabile, A. (1990). Playground activities for boys and girls: Some developmental and cultural trends in children's perceptions of gender differences. Play and Culture, 3, 343-347.

Corsaro, W. (1985). Friendship and peer culture in the early years. Norwood: Ablex.

Corsaro, W. A, \& Molinari, L. (1990). From seggiolini to discussione: The generation and extension of peer culture among Italian preschool children. Qualitative Studies in Education, 3, 213-320.

Eibl-Eibesfeldt, I. (1989). Human Ethology. New York: Aldine de Gruyter. Geertz, C. (1973). The interpretation of cultures: Selected essays. New York: Basic Books.

Harris, J. R. (1995). Diga-me com quem anda... São Paulo: Objetiva.

Hinde, R. A. (1974). Biological basis of human social behaviour. New York: McGraw.

Hinde, R. A. (1987). Individuals, relationships and culture - Links between ethology and the social sciences. New York: Cambridge University Press.

Løkken, G. (2001). Toddler peer culture: estilo social de sujeitos-corporais de um e dois anos de idade na interação cotidiana [Resumo]. Anais do II Encontro Norte-Nordeste de Psicologia [CD-Rom]. Salvador, BA.

Lorenz, K. (1966). Evolution of ritualization in the biological and cultural spheres. Philosophical Transactions of the Royal Society of Britain, 251, 273-284.

Moraes, M. L. S., \& Carvalho, A. M. A. (1994). Faz-de-conta: temas, papéis e regras na brincadeira de crianças de quatro anos. Boletim de Psicologia, 44, 21-30.

Morin, E. (1979). O enigma do homem: para uma nova antropologia. Rio de Janeiro: Zahar.

Oliveira, Z. M. R. (1995). A criança e seu desenvolvimento: perspectivas para se discutir a educação infantil. São Paulo: Cortez.

Pedrosa, M. I. (1989). Interação criança-criança: um lugar de construção do sujeito. Tese de doutorado não-publicada, Universidade de São Paulo, São Paulo.

Pedrosa, M. I., \& Carvalho, A. M. A. (1995). A interação social e a construção da brincadeira. Cadernos de Pesquisa, 93, 60-65.
Pedrosa, M. I., Carvalho, A. M. A., \& Império-Hamburger, A. (1997). From disordered to ordered movement: Attractor configuration and development. In A. Fogel, M. Lyra \& J. Valsiner (Orgs.), Dynamics and indeterminism in developmental and social processes (pp. 135151). Mahwah: LEA.

Pedrosa, M. I., \& Eckerman, C. O. (2000). Sharing means: How infants construct joint action from movement, space, and objects. In International Society for the Study of Behavioural Development (ISSBD) (Org.), Abstracts of the XVIth Biennial Meetings of ISSBD (p. 438). Beijing: ISSBD.

Pedrosa, M. I., \& Santos, M. F. (2000). Ontogeny of social representations in young children. In F. Y. Doré (Org.), International Journal of Psychology - Abstracts of the XXVII International Congress of Psychology: Vol. 35, 161. Stockholm: Psychology Press.

Pino, A. (1993). Processos de significação e constituição do sujeito. Temas em Psicologia, 1, 17-24.

Pontes, F. A. R., \& Magalhães, C. M. C. (no prelo). A transmissão da cultura da brincadeira: algumas possibilidades de investigação. $P s i-$ cologia, Reflexão e Crítica.

Rabinovich, E. P., \& Carvalho, A. M. A. (2001). Modo de morar e modo de cuidar: uma proposta de tipologia. Psicologia Ciência e Profissão, 21, 74-85.

Rossetti-Ferreira, M. C., Amorim, K., \& Vitória, T. (1996). Emergência de novos significados durante o processo de adaptação de bebês à creche. In M. I. Pedrosa (Org.), Coletâneas da ANPEPP: Vol. 1. Investigação da criança em interação social (pp. 111-143). Recife: Editora Universitária da Universidade Federal de Pernambuco.

Rossetti-Ferreira, M. C., Amorim, K., \& Vitória, T. (1997). Integração família e creche: o acolhimento é o princípio de tudo. In E. M. Marturano, S. R. Loureiro \& A. W. Zuardi (Orgs.), Estudos em Saúde Mental 1997 do Curso de Pós-graduação em Saúde Mental da Faculdade de Medicina de Ribeirão Preto-USP (pp. 109-131). Ribeirão Preto: USP.

Stamback, M., \& Verba, M. (1986). Organization of social play among toddlers: an ecological approach. In E. Mueller, \& C. Cooper (Orgs.), Process and outcome in peer relationships (p. 229-247). New York: Academic Press.

Tomasello, M., Kruger, A. C., \& Ratner, H. H. (1993). Cultural learning. Behavioral and Brain Sciences, 16, 495-511.

Valsiner, J. (1991) Construction of the mental: from the 'cognitive revolution' to the study of development. Theory and Psychology, 1, 477-494.

Verba, M. (1994). The beginnings of collaboration in peer interaction. Human Development, 37, 125-139.

Vitória, T., \& Rossetti-Ferreira, M. C. (1993). Processos de adaptação na creche. Cadernos de Pesquisa, 86, 55-64.

Vygotsky, L. S. (1984). A formação social da mente. São Paulo: Martins Fontes. Wallon, H. (1979). Do acto ao pensamento: ensaio de psicologia comparada $\left(2^{\mathrm{a}}\right.$ ed.). Lisboa: Moraes (Texto original publicado em 1942).

Ana Maria Almeida Carvalho, doutor em Psicologia pela Universidade de São Paulo, São Paulo, SP, é Professor associado (aposentado) do Instituto de Psicologia da Universidade de São Paulo, SP. Pesquisador bolsista do CNPq. Apoio FAPESP.

Maria Isabel Pedrosa, doutor em Psicologia pela Universidade de São Paulo, é professor adjunto do Departamento de Psicologia da Universidade Federal de Pernambuco, Recife, PE. Pesquisador bolsista do CNPq.

Endereço para correspondência: [AMAC] Rua da Invernada, 12, Fazendinha, 06355-340, Carapicuiba, SP. Telefone/fax (11)4169.8732. E-mail: amacarva@uol.com.br. [MIP] Rua Dom Miguel de Lima Valverde, 88/1001. Espinheiro, 52020-120, Recife, PE. Telefone/fax: (81)3427.9568. E-mail: icpedrosa@uol.com.br. 